\title{
TINGKAT KESEJAHTERAAN KELUARGA PETANI KELAPA DI DESA KLABAT KECAMATAN DIMEMBE KABUPATEN MINAHASA UTARA
}

\author{
Keren Pratiwi Umar \\ Jane Sulinda Tambas \\ Martha Mareyke Sendow
}

\begin{tabular}{ll}
\hline Naskah diterima melalui Email agrisosioekonomi@unsrat.ac.id & : Jumat, 17 Juli 2020 \\
Disetujui diterbitkan & : Selasa, 21 Juli 2020 \\
\hline
\end{tabular}

\begin{abstract}
This study aims to determine and see the level of welfare of coconut farming family in Klabat Village, Dimembe Sub-district, North Minahasa Regency. This research was conducted in February to May 2020. Sampling used purposive sampling method. Data collection was obtained through direct interviews with the help of a questionnaire, to 40 respondents who are the family head of coconut farming family heads, based the concepts and indicators of the 2015 version of the National Population and Family Planning Agency (Badan Kependudukan dan Keluarga Berencana Nasional or BKKBN) which consists of 5 stages of family welfare indicators. Data analysis used descriptive analysis method by making tables and percentages to explain the level of welfare of farmers' families in Klabat Village. The results showed that most coconut farming families were included in the category of prosperous families II (KS II). Another finding is that there are still families of KS I who have not been able to reach the level of welfare of KS II, because most of them are due to indicators of families of fertile age couples with two or more children using contraceptive devices / drugs, which have not yet been fulfilled. KS II families cannot become KS III families, because it is largely due to indicators of family income saved in the form of money or goods, which cannot be fulfilled yet. The KS III family cannot yet become the KS III plus family, because it is largely due to the indicators of the role in the community, which cannot yet be fulfilled. ${ }^{*}$ prm*
\end{abstract}

Keywords: coconut farmers, family welfare, National Population and Family Planning Agency (BKKBN)

ABSTRAK

Penelitian ini bertujuan untuk mengetahui dan melihat tingkat kesejahteraan keluarga petani kelapa di Desa Klabat Kecamatan Dimembe Kabupaten Minahasa Utara. Penelitian ini dilaksanakan pada bulan Febuari sampai dengan Mei 2020. Penggambilan sampel menggunakan metode secara sengaja (purposive sampling). Pengumpulan data diperoleh melalui wawancara langsung dengan bantuan kuesioner kepada 40 responden kepala keluarga petani kelapa dengan menggunakan konsep dan indikator dari Badan Kependudukan dan Keluarga Berencana Nasional (BKKBN) versi tahun 2015 yang mencakup 5 tahapan indikator kesejahteraan keluarga. Analisis data menggunakan metode analisis deskriptif dengan membuat tabel dan persentase untuk menjelaskan tingkat kesejahteraan keluarga petani di Desa Klabat. Hasil penelitian menunjukkan bahwa kebanyakan keluarga petani kelapa masuk pada kategori keluarga sejahtera II (KS II). Hasil temuan lain adalah masih adanya keluarga KS I belum bisa mencapai tingkat kesejahteraan KS II, karena sebagian besar karena indikator keluarga pasangan usia subur dengan dua anak atau lebih menggunakan alat/obat kontrasepsi, belum bisa terpenuhi. Keluarga KS II belum bisa menjadi keluarga KS III, karena sebagian besar disebabkan indikator penghasilan keluarga yang ditabung dalam bentuk uang atau barang, belum bisa terpenuhi. Keluarga KS III belum bisa menjadi keluarga KS III plus, karena sebagian besar disebabkan indikator peran dalam masyarakat, belum bisa terpenuhi. ${ }^{*}{ }^{*}$ rm ${ }^{*}$

Kata kunci : petani kelapa, kesejahteraan keluarga, Badan Kependudukan dan Keluarga Berencana Nasional (BKKBN) 


\section{PENDAHULUAN}

\section{Latar Belakang}

Negara Indonesia memiliki pertumbuhan jumlah penduduk yang tinggi, sehingga berdampak pada kesejahteraan rakyat. Kesejahteraan dalam pemenuhan kebutuhan hidup dapat dilihat dari jumlah pengeluaran penduduk. Besar kecilnya jumlah pengeluaran penduduk bukan untuk makanan terhadap seluruh pengeluaran, dapat merupakan salah satu cerminan kesejahteraan penduduk. Makin besar jumlah tersebut menunjukkan semakin tinggi tingkat kesejahteraan.

Menurut Sunarti (2011), kesejahteraan adalah suatu tata kehidupan dan penghidupan sosial, material, maupun spiritual. Kesejahteraan pada hakekatnya terdiri dari dua dimensi yaitu kesejahteraan secara ekonomi (family wellbeing) yang diukur oleh pemenuhan input keluarga (misalnya diukur dari pendapatan, upah, asset dan pengeluaran keluarga) dan kesejahteraan material (family materilal wellbeing) yang diukur dari beberapa bentuk barang dan jasa yang diakses oleh keluarga. Kesejahteraan yang subjektif juga dapat diperoleh dengan menanyakan langsung pada keluarga bagaimana pendapat/persepsi kesejahteraan yang merupakan kenyataan dan diperoleh melalui pengalaman hidup sehari-hari dalam hubungannya dengan lingkungan keluarga, kelompok dan masyarakat untuk mencapai kesejahteraan hidup.

Indonesia sebagai Negara agraris, sebagian penduduknya berprofesi sebagai petani. Para petani memenuhi kebutuhan pangan keluarganya dengan hasil pertanian yang dimiliki. Dalam hal pemenuhan kebutuhan petani seharusnya mempunyai nilai tawar yang tinggi dan kesejahteraan mereka diperhatikan oleh pemerintah. Tanaman Kelapa merupakan salah satu komoditas strategis yang memiliki peran sosial, budaya, dan ekonomi dalam kehidupan masyarakat Indonesia. Menurut Karsyno dan Fasial dalam Ikbal (2014), mengemukakkan bahwa sumber pendapatan keluarga petani dapat dikelompokkan menjadi pendapatan dari usahatani, non usahatani, dan luar sektor pertanian.
Kondisi petani di Provinsi Sulawesi Utara dinilai belum sejahtera, hal ini dibuktikan dengan Nilai Tukar Petani (NTP) Sulut yang masih dibawah 100, keadaan ini menunjukkan daya beli petani secara umum belum membaik dibandingkan kondisi pada 2012. Berdasarkan data Badan Pusat Statistik (BPS) untuk bulan Februari 2019 NTP petani berada di angka 95,41 atau turun 0,24\% dari NTP bulan sebelumnya 95,18. Penurunan disebabkan oleh kenaikan harga barang-barang kebutuhan rumah tangga serta biaya produksi dan penambahan barang modal. (BPS, 2019).

Sulawesi Utara merupakan salah satu provinsi dengan tingkat pendapatan ekonomi dari sektor pertanian yang cukup tinggi. Salah satu daerah yang mempunyai potensi bidang pertanian adalah Kabupaten Minahasa Utara, khususnya di Desa Klabat mayoritas masyarakat bekerja sebagai petani kelapa. Sebagai komoditas andalan, kelapa memegang peranan penting bagi perkembangan dan pertumbuhan ekonomi keluarga. Upaya memperbaiki tingkat upah dan kesejahteraan buruh tani menghadapi permasalahan yang kompleks (Sumaryanto dan Rusastra 2000 dalam Rusastra dan Suryadi 2004). Kehidupan masyarakat petani kelapa, tidak semuanya hidup dalam tingkat kesejahteraan yang memadai, banyak dari petani kelapa menjual kebun kelapa mereka, karena biaya tenaga kerja yang cukup tinggi dan hasil yang di dapat oleh petani kelapa belum bisa mencukupi kebutuhan hidup keluarga. Oleh sebab itu, petani kelapa melakukan pekerjaan sampingan seperti, menanam papaya, pisang dan ubi. Bahkan beralih profesi sebagai, angkutan pasir dalam hal ini pemilik mobil, pemilik lahan dan sebagai tenaga kerja angkutan pasir, adapun bekerja sebagai supir truck, tukang ojek dan lain-lain. Dalam hal ini peran masyarakat petani sangat penting dalam meningkatkan potensi tanaman kelapa yang berada di Desa Klabat agar bisa memproduksi tanaman kelapa lebih banyak lagi sehingga keluarga petani kelapa hidup dalam kesejahteraan yang di inginkan. Mengenai kesejahteraan keluarag petani kelapa, Badan Kependudukan dan Keluarga Berencana Nasional (BKKBN) mengklasifikasikan keluarga sejahtera ke dalam lima kategori, yaitu keluarga : Pra Sejahtera, Sejahtera I, Sejahtera II, Sejahtera III dan Sejahtera III plus, yang digunakan dalam tingkat kesejahteraan petani 
kelapa dalam segi sosial dan ekonomi. Kesejahteraan yang dimaksud adalah kebutuhan standar hidup yang harus terpenuhi oleh keluarga petani kelapa. Diharapkan pemerintah memiliki strategi dalam upaya mempertahankan dan meningkatkan kesejahteraan petani.

Berdasarkan uraian tersebut, penulis tertarik untuk melakukan penelitian tentang "Tingkat Kesejahteraan Keluarga Petani Kelapa di Desa Klabat, Kecamatan Dimembe, Kabupaten Minahasa Utara”.

\section{Konsep Kesejahteraan}

\section{Menurut Soembodo}

(2006),

Kesejahteraan secara umum dapat diartikan sebagai tingkat kemampuan seseorang dalam memenuhi kebutuhan primernya (basic needs) berupa sandang, pangan, papan, pendidikan, dan kesehatan. Menurut Sawidak 1985 dalam Liby, (2017), kesejahteraan merupakan sejumlah kepuasan yang diperoleh seseorang dari hasil mengkonsumsi pendapatan yang diterima.

\section{Teori Indikator Keluarga Sejahtera}

Keluarga Sejahtera adalah keluarga yang dibentuk berdasarkan atas perkawinan yang sah, mampu memenuhi kebutuhan hidup spiritual dan materiil yang layak, bertaqwa kepada Tuhan Yang Maha Esa, memiliki hubungan yang serasi, selaras dan seimbang antar anggota dan antar keluarga dengan masyarakat dan lingkungan (Undang-Undang Republik Indonesia Nomor 52 tahun 2009). Badan Kependudukan dan Keluarga Berencana Nasional (BKKBN) mendefinisikan miskin berdasarkan konsep/ pendekatan kesejahteraan keluarga, yaitu dengan membagi kriteria keluarga ke dalam lima tahapan, yaitu keluarga pra sejahtera (KPS), keluarga sejahtera I (KS-I), keluarga sejahtera II (KS-II), keluarga sejahtera III (KS-III), dan keluarga sejahtera III plus (KS-III Plus).

\section{Kajian Tentang Petani}

\section{Pengertian Petani}

Pertanian adalah suatu kegiatan manusia yang termasuk di dalamnya yaitu bercocok tanam, peternakan, perikanan dan juga kehutanan.

\section{Usahatani}

Usahatani merupakan cara-cara menentukan, mengorganisasikan, dan mengkoordinasi penggunaan faktor-faktor produksi seefektif dan seefisien mungkin sehingga usaha tersebut memberikan pendapatan semaksimal mungkin (Suratiyah, 2008).

Lahan pertanian merupakan sumber pendapatan untuk rumah tangga petani sehingga dapat dijadikan sebagai indikator tingkat kesejahteraan meskipun tidak sepenuhnya dapat mencerminkan tingkat kesejahteraan yang sebenarnya (Saptana dan Rozi, 2014 dalam Pratiwi dan Rondhi 2018). Kepemilikan lahan pertanian dapat dibagi ke dalam beberapa kategori yaitu sebagai berikut: petani pemilik, petani penggarap dan petani pemilik penggarap.

\section{Keluarga Petani}

Keluarga petani ialah keluarga yang kepala keluarga atau anggota keluarganya bermata pencarian sebagai Petani. Keluarga Petani mendapat penghasilan utama dari kegiatan bertani untuk memenuhi kebutuhan hidupnya. Menurut Purbangkoro 1994 dalam Bertham, dkk (2011), Pendapatan keluarga ialah sejumlah penghasilan dari keluarga (penghasilan dari suami, istri dan anggota keluarga lainnya.

\section{Rumusan Masalah}

Adapun rumusan masalah dalam penelitian ini adalah bagaimana Tingkat Kesejahteraan Keluarga Petani Kelapa di Desa Klabat, Kecamatan Dimembe, Kabupaten Minahasa Utara?

\section{Tujuan Penelitian}

Penelitian ini bertujuan adalah untuk mengetahui dan melihat Tingkat Kesejahteraan Keluarga Petani Kelapa di Desa Klabat, Kecamatan Dimembe, Kabupaten Minahasa Utara.

\section{Manfaat Penelitian}

Manfaat dari penelitian ini yaitu:

1. Sebagai tambahan pengetahuan tentang Tingkat Kesejahteraan keluarga petani Kelapa di Desa Klabat.

2. Sebagai informasi bagi keluarga petani untuk bisa menggembangkan komoditas kelapa dalam meningkatkan kesejahteraan keluarga.

3. Sebagai informasi bagi pemerintah dalam memperhatikan kesejahteraan keluarga petani kelapa yang ada di Desa Klabat. 


\section{METODE PENELITIAN}

\section{Tempat dan Waktu Penelitian}

Penelitian dilakukan di Desa Klabat, Kecamatan Dimembe, Kabupaten Minahasa Utara. Kegiatan penelitian dilakukan sejak bulan Febuari hingga bulan Mei 2020 mulai dari persiapan sampai penyusunan laporan hasil penelitian.

\section{Metode Pengambilan Sampel}

Metode yang digunakan dalam pengambilan sampel adalah secara random sampling yaitu sampel yang diambil secara acak. Populasi penelitian ini adalah keluarga petani kelapa yang ada di Desa Klabat, yang kepala keluarganya mempunyai pekerjaan sebagai petani berjumlah 450 orang, namun tidak semua sebagai petani kelapa dan kemudian diambil sampel sebanyak 40 kepala keluarga petani kelapa, karena di Desa Klabat terdiri dari delapan lingkungan dan setiap lingkungan diambil 5 responden petani kelapa menggunakan kuesioner untuk mengambil data sesuai dengan tujuan penulisan.

\section{Konsep dan Indikator}

Kajian keadaan tingkat kesejahteraan petani kelapa berdasarkan kriteria dari BKKBN yang meliputi 5 tahapan indikator kesejahteraan keluarga. Tingkat kesejahteraan merupakan kemampuan petani di Desa Klabat Kecamatan Dimembe Kabupaten Minahasa Utara. Konsep dari BKKBN merujuk pada kesejahteraan keluarga petani dalam memenuhi kebutuhan pokok, baik itu kebutuhan akan makanan, pakaian, tempat tinggal, serta kesempatan untuk melanjutkan pendidikan dan memiliki pekerjaan yang memadai yang dapat menunjang kualitas hidup sehingga memiliki status sosial yang sama terhadap sesama warga lainnya.

\section{Analisis Data}

Analisis data dalam penelitian ini menggunakan metode analisis deskriptif dengan membuat tabel dan persentase untuk menjelaskan tingkat kesejahteraan keluarga petani di Desa Klabat.

\section{HASIL DAN PEMBAHASAN}

\section{Deskripsi Umum Lokasi Penelitian}

\section{Sejarah Desa}

Desa Klabat merupakan salah satu Desa di Wilayah Kecamatan Dimembe, yang terletak di bagian Timur Kecamatan Dimembe Kabupaten Minahasa Utara dan berbatasan dengan Kota Bitung. Wanua Klabat dibuka sejak tahun 1924 oleh orang-orang yang berasal dari Wanua Tatelu dan Airmadidi, dibawah pimpinan orang tua asal Wanua Tatelu. Desa ini berada di dibawah kaki Gunung Klabat yang merupakan gunung api setinggi $1.995 \mathrm{mdpl}$, keberadaan Desa Klabat yang berada di kaki gunung, menjadikan Desa Klabat masuk dalam kawasan konservasi alam hutan Klabat Ketinggian dari dasar laut 450 sampai 600 meter. Dengan suhu rata-rata 23 sampai dengan 29 derajat celcius. Curah hujan tidak menentu.

Adapun Batas-batas Wilayah Desa Klabat sebagai yaitu :

Sebalah Utara : berbatasan dengan Baris Kepolisian Desa Pinilih dan Hutan Mawiau

Sebelah Timur : berbatasan dengan Kelurahan Karondoran, Perkebunan Kelurahan Kumersot Kota Bitung

Sebelah Selatan berbatasan dengan Gunung Klabat Sebelah Barat berbatasan dengan Baris Kepolisian Desa Pinilih

Topografi datar. Dengan kesuburan tanah yang menghasilkan berbagai komoditi unggulan seperti Kelapa, Cengkih, Pala, Buah-buahan Pepaya, Pisang dan tanaman ubi-ubian lainnya. Sarana dan prasarana umum di desa ini yaitu bangunan Sekolah terdapat: taman kanak-kanak (TK) 1 unit, Sekolah Dasar (SD) 3 unit. Bangunan tempat ibadah terdapat: GMIM 2 unit, GPdI 1 unit, Mesjid 2 unit, dan Advent 1 unit.

\section{Keadaan Penduduk}

Desa Klabat terdiri delapan lingkungan dan memiliki jumlah penduduk sebanyak 2.824 jiwa, dengan jumlah kepala keluarga $470 \mathrm{KK}$. Dengan demikian jumlah rata-rata anggota per keluarga sebanyak 5 orang. Secara terperinci jumlah penduduk di Desa Klabat dapat dilihat pada Tabel 1. 
Tabel 1. Jumlah Penduduk Menurut Jenis Kelamin

\begin{tabular}{cccr}
\hline No & Jenis Kelamin & $\begin{array}{c}\text { Jumlah } \\
\text { (Jiwa) }\end{array}$ & Persentase (\%) \\
\hline 1. & Laki Laki & 1,238 & 43,83 \\
2. & Perempuan & 1,586 & 56,17 \\
\hline & Jumlah & 2.824 & 100 \\
\hline
\end{tabular}

Sumber : Data Desa Klabat, 2020

Tabel 1 menunjukkan bahwa jumlah penduduk perempuan lebih banyak dibandingkan laki-laki. Pekerjaan yang ditekuni penduduk di Desa Klabat yaitu bertani atau mengembangkan usaha di bidang non pertanian.

\section{Karakteristik Responden}

\section{Umur Responden}

Umur yang diambil dalam satuan tahun dapat mempengaruhi produktifitas petani dalam pekerjaan yang dilakukan. Menurut hasil penelitian, umur responden dapat dilihat dalam Tabel 2.

Tabel 2. Distribusi Responden Menurut Umur

\begin{tabular}{clcr}
\hline No & Umur & Jumlah Responden & Persentase $(\%)$ \\
\hline 1. & $<49$ & 10 & 25 \\
2. & $50-59$ & 11 & 27.5 \\
3. & $60-69$ & 12 & 30 \\
4. & $70-79$ & 5 & 12.5 \\
5. & $>80$ & 2 & 5 \\
\hline & Jumlah & 40 & 100 \\
\hline
\end{tabular}

Sumber : Data Primer yang diolah, 2020

Tabel 2 menunjukkan bahwa sebagian besar responden petani berumur 50-69 tahun sebanyak 57,5\%, petani kelapa di Desa Klabat didominasi lanjut usia. Hal ini karena sebagian besar kepala keluarga petani kelapa di Desa Klabat masih kuat bekerja dan beraktivitas dengan semangat sebagai petani kelapa karena mereka telah terbiasa melakukan pekerjaan itu.

\section{Tingkat Pendidikan}

Peranan pendidikan formal sangat penting dalam usaha peningkatan kualitas seseorang karena berguna dalam pembangunan pribadi serta peningkatan intelektual dan wawasan seseorang. Tingkat Pendidikan petani kelapa dapat dilihat pada Tabel 3.
Tabel 3. Tingkat Pendidikan Terakhir yang ditempuh Kepala Keluarga Petani Kelapa di Desa Klabat

\begin{tabular}{clcr}
\hline No & $\begin{array}{c}\text { Tingkat } \\
\text { Pendidikan }\end{array}$ & $\begin{array}{c}\text { Jumlah } \\
\text { Responden }\end{array}$ & Persentase (\%) \\
\hline 1. & SD & 15 & 37.5 \\
2. & SMP & 13 & 32.5 \\
3. & SMA & 7 & 17.5 \\
4 & D1-D3 & 1 & 2.5 \\
5. & S1 & 4 & 10 \\
\hline \multicolumn{5}{r}{ Jumlah } & 40 & 100 \\
\hline \multicolumn{5}{l}{ Sumber : Data Primer yang diolah, 2020}
\end{tabular}

Tabel 3 menunjukkan bahwa pendidikan terakhir yang ditempuh kepala keluarga petani kelapa di Desa Klabat terbanyak adalah jenjang pendidkan umum sebagian besar pendidikan SD dan SMP sebanyak 70\%. Dan paling rendah tingkat pendidikan Diploma.

\section{Pendapatan Petani}

Pendapatan petani merupakan penerimaan yang dikurangi dengan biaya-biaya yang dikeluarkan dalam usahatani dan pemasaran hasil pertanian.

Tabel 4. Tingkat Pendapatan Responden Petani Kelapa di Desa Klabat

\begin{tabular}{cccr}
\hline No & Kelapa & Jumlah & Persentase (\%) \\
\hline 1. & $>1.000,000$ & 2 & 5 \\
2. & $<1.000,000-2.000,000$ & 25 & 62,5 \\
3. & $<2.000,000-3.000,000$ & 7 & 17.5 \\
4 & $<3.000,000-4.000,000$ & 1 & 2.5 \\
5. & $<4.000,000-5.000,000$ & 2 & 5 \\
6. & $<5.000,000$ & 3 & 7,5 \\
\hline & Jumlah & 40 & 100 \\
\hline
\end{tabular}

Sumber : Data Primer yang diolah, 2020

Tabel 4 menunjukkan bahwa sebanyak $60 \%$ yang memiliki pendapatan diatas Rp. 1.000,000 sampai dengan Rp. 2.000,000 sebulan. Pendapatan petani kelapa di Desa Klabat menurun karena harga jual kelapa rendah sehingga pendapatan petani kelapa belum dapat mencukupi kebutuhan keluarga sedangkan pengeluaran keluarga cukup besar. Oleh karena itu, petani melakukan pekerjaan sampingan untuk memenuhi kebutuhan hidupnya dalam mensejahterakan keluarga.

\section{Pengalaman Usaha Tani}

Pengalaman dalam bertani juga mempengaruhi penghasilan apabila sudah lama menekuni pekerjaan, pastinya petani sudah mengetahui hal baik maupun buruk selama bekerja dan Hal-hal baik pasti ada dilakukan agar supaya mendapat hasil yang baik pula. Pengalaman bertani responden dapat dilihat pada Tabel 5. 
Tabel 5. Tingkat Pengalaman Bertani Responden Kelapa di Desa Klabat

\begin{tabular}{cccr}
\hline No & $\begin{array}{c}\text { Lama Menjadi } \\
\text { Petani }\end{array}$ & $\begin{array}{c}\text { Jumlah } \\
\text { Responden }\end{array}$ & Persentase (\%) \\
\hline 1 & $<10$ & 7 & 17.5 \\
2 & $15-20$ & 11 & 27.5 \\
3 & $21-30$ & 4 & 10 \\
4 & $31-40$ & 16 & 40 \\
5 & $41-45$ & 1 & 2.5 \\
6 & $46-50$ & 1 & 2.5 \\
\hline \multicolumn{4}{c}{ Jumlah } \\
\hline Sumber : Data Primer yang diolah, 2020
\end{tabular}

Tabel 5 menunjukkan bahwa petani di Desa Klabat sebagian besar 50\%, telah menekuni pekerjaan sebagai petani selama 21 sampai dengan 40 tahun yang sudah dapat dikatakan telah lama bertani kelapa, yang seharusnya telah dapat mengatasi setiap kesulitan-kesulitan dalam berusaha tani dan mampu menjawab pertanyaan dalam bidangnya.

\section{Kepemilikan Lahan}

Kepemilikan lahan petani di Desa Klabat cukup besar dan kebanyakan lahan-lahan yang ada merupakan warisan untuk generasi selanjutnya. Data kepemilikan lahan responden petani kelapa di Desa Klabat dapat dilihat pada Tabel 6.

Tabel 6. Kepemilikan Lahan Responden Petani Kelapa di Desa Klabat

\begin{tabular}{llcr}
\hline No & \multicolumn{1}{c}{ Status } & $\begin{array}{c}\text { Jumlah } \\
\text { Responden }\end{array}$ & Persentase (\%) \\
\hline 1 & Pemilik & 35 & 87.5 \\
2 & Pemilik dan Penggarap & 3 & 7.5 \\
3 & Sewa & 2 & 5 \\
\hline \multicolumn{2}{r}{ Jumlah } & 40 & 100 \\
\hline
\end{tabular}

Sumber : Data Primer yang diolah, 2020

Tabel 6 menunjukkan bahwa status kepemilikan lahan petani sebanyak 87,5\% adalah sebagai pemilik lahan. Di Desa Klabat memang paling banyak petani yang mempunyai lahan sendiri dibandingkan penggarap maupun sewa. Hal ini seharusnya bisa membantu petani kelapa di Desa Klabat hidup di tingkat kesejahteraan yang memadai.

\section{Status Rumah Tinggal}

Rumah tinggal merupakan sebuah tempat perteduhan setiap warga atau masyarakat yang telah dimiliki seutuhnya. Status rumah tinggal responden dilihat pada Tabel 7.
Tabel 7. Status Rumah Tinggal Responden Petani Kelapa di Desa Klabat

\begin{tabular}{clcr}
\hline No & \multicolumn{1}{c}{ Status } & Jumlah Responden & Persentase (\%) \\
\hline 1 & Milik Sendiri & 33 & 82.5 \\
2 & Orangtua & 2 & 5 \\
3 & Menumpang & 1 & 2.5 \\
\hline & Jumlah & 40 & 100 \\
\hline
\end{tabular}

Sumber : Data Primer yang diolah, 2020

Tabel 7 menunjukkan bahwa sebanyak $82,5 \%$ memiliki status rumah Tinggal milik sendiri, selanjutnya terdapat sebanyak 5\% milik orangtua, dan sebanyak 2,5\% Menumpang. Jadi, status rumah tinggal petani sebagian adalah milik sendiri sebanyak 33 orang dan 2 orang milik orangtua. Hal ini menjelaskan bahwa petani kelapa dapat memenuhi rumah sendiri dengan bertani kelapa.

\section{Tingkat Kesejahteraan Keluarga di Desa Klabat}

\section{Tingkat Kesejahteraan Keluarga Petani Kelapa di Desa Klabat}

Penelitian ini mengetahui sejauh mana tingkat kesejahteraan keluarga petani di Desa Klabat berdasarkan tahapan kesejahteraan yang dikembangkan oleh BKKBN. Terdiri dari 21 indikator dan dibagi menjadi 5 tahapan yaitu Keluarga Pra Sejahtera (KPS), Keluarga Sejahtera Tahap I (KS I), Keluarga Sejahtera Tahap II (KS II), Keluarga Sejahtera Tahap III (KS III) dan Keluarga Sejahtera Tahap III+ (KS III+).

Tabel 8. Tingkat Kesejahteraan Berdasarkan Tahapan Kesejahteraan Keluarga

\begin{tabular}{clcr}
\hline No & Tngkat Kesejahteraan & Jumlah (Petani) & Persentase (\%) \\
\hline 1 & Keluarga Pra Sejahtera & - & 0 \\
2 & KS I & 10 & 25 \\
3 & KS II & 16 & 40 \\
4 & KS III & 7 & 17.5 \\
5 & KS III+ & 7 & 17.5 \\
\hline \multicolumn{2}{r}{ Jumlah } & 40 & 100 \\
\hline \multicolumn{2}{l}{ Sumber : Data Primer yang diolah, 2020 }
\end{tabular}

Tabel 8 menunjukkan bahwa tidak terdapat keluarga petani kelapa yang termasuk dalam Keluarga Pra Sejahtera (KPS). Sementara persentase terbanyak ada pada Keluarga Sejahtera Tahap II (KS II) yaitu sebesar $40 \%$ diikuti Keluarga Sejahtera Tahap I (KS I) sebanyak 25\% dan Keluarga Sejahtera Tahap III dan III + sebanyak 17,5\%. Petani-petani yang tidak memenuhi salah satu indikator dari BKKBN ini bukan berarti tidak dapat memenuhi indikator 
selanjutnya, dikarenakan sistem pentahapan berbentuk hierarki yang merupakan ciri dan model pengukuran kesejahteraan keluarga untuk mendapatkan tingkat kesejahteraan yang sesungguhnya.

Adapun distribusi tingkat kesejahteraan keluarga petani kelapa Desa Klabat berdasarkan indikator kesejahteraan yang masih belum bisa terpenuhi dapat dilihat pada Tabel 9.

Tabel 9. Keluarga Sejahtera Tahap I (KS I) Berdasarkan Indikator yang Tidak Terpenuhi

\begin{tabular}{|c|c|c|c|}
\hline \multirow[t]{2}{*}{ TINGKAT KS } & \multirow{2}{*}{$\begin{array}{c}\text { Indikator yang Tidak } \\
\text { Terpenuhi }\end{array}$} & \multicolumn{2}{|c|}{ Jumlah } \\
\hline & & $\mathrm{F}$ & $\%$ \\
\hline & $\begin{array}{l}\text { 1. Seluruh anggota keluarga } \\
\text { memperoleh paling kurang } \\
\text { satu stel pakaian baru } \\
\text { dalam Setahun }\end{array}$ & 1 & 10 \\
\hline & $\begin{array}{l}\text { 2. Tiga bulan terakhir } \\
\text { keluarga dalam keadaan } \\
\text { sehat sehingga dapat } \\
\text { melaksanakan tugas/ } \\
\text { fungsi masing-masing }\end{array}$ & 2 & 12,5 \\
\hline \multirow[t]{4}{*}{ KS I } & $\begin{array}{l}\text { 3. Pasangan usia subur } \\
\text { dengan dua Anak atau } \\
\text { lebih menggunakan } \\
\text { alat/obat kontrasepsi }\end{array}$ & 4 & 45 \\
\hline & $\begin{array}{l}\text { 4. Seluruh anggota keluarga } \\
\text { umur } 10-60 \text { tahun bisa } \\
\text { baca tulis latin }\end{array}$ & 1 & 2.5 \\
\hline & $\begin{array}{l}\text { 5. Ada seorang atau lebih } \\
\text { anggota keluarga yang } \\
\text { bekerja untuk memperoleh } \\
\text { Penghasilan }\end{array}$ & 2 & 30 \\
\hline & Jumlah & 10 & 100 \\
\hline
\end{tabular}

Sumber : Data Primer yang diolah, 2020

Tabel 9 menunjukkan bahwa sebanyak 45\% keluarga petani yang berada pada KS I belum bisa mencapai KS II karena indikator keluarga berencana yaitu pasangan usia subur dengan dua anak atau lebih menggunakan alat/obat kontrasepsi belum dapat terpenuhi. Selanjutnya indikator yang tidak dapat dipenuhi keluarga petani dengan tingkat kesejahteraan KS I adalah ada seorang atau lebih anggota keluarga yang memperoleh penghasilan sebanyak $30 \%$ dan di ikuti indikator yang lainnya.

Keluarga petani Kelapa di Desa Klabat yang masuk ke dalam kategori KS II menjadi terbanyak pertama. Dari 40 keluarga petani yang dijadikan sampel, sebanyak 16 keluarga atau $40 \%$ masuk pada kategori ini. Keluarga pada tingkat KS II ini belum bisa menjadi keluarga KS III karena ada indikator KS III yang masih belum bisa mereka penuhi, paling banyak indikator penghasilan dalam keluarga, ada juga yang masih belum memenuhi indikator interaksi dalam keluarga. Selengkapnya dapat dilihat pada Tabel 10.

Tabel 10. Keluarga Sejahtera Tahap II (KS II) Berdasarkan Indikator yang Tidak Terpenuhi

\begin{tabular}{clcc}
\hline TINGKAT KS & \multicolumn{2}{c}{ Indikator yang Tidak } & \multicolumn{2}{c}{ Jumlah } \\
& \multicolumn{1}{c}{ Terpenuhi } & F & $\%$ \\
\hline & $\begin{array}{l}\text { 1. Sebagian penghasilan } \\
\text { keluarga di tabung } \\
\text { dalam bentuk uang }\end{array}$ & & \\
& atau barang & & \\
KS II & & & \\
& $\begin{array}{l}\text { 2. Kebiasaan keluarga } \\
\text { makan bersama paling } \\
\text { kurang seminggu sekali } \\
\text { dimanfaatkan untuk } \\
\text { berkomunikasi }\end{array}$ & & \\
& & & \\
\hline Jumlah & & \\
\hline Sumber : Data Primer yang diolah, 2020 & & \\
\hline
\end{tabular}

Tabel 10 menunjukkan bahwa sebanyak 16 petani atau $40 \%$ termasuk dalam KS II dengan indikator yang tidak dapat dipenuhi sebagian besar adalah penghasilan keluarga yaitu sebagian penghasilan keluarga dalam bentuk uang atau barang sebanyak $52,5 \%$ dan indikator interaksi dalam keluarga yaitu keluarga makan bersama seminggu sekali digunakan untuk berkomunikasi sebanyak sebanyak 47,5\%.

Keluarga petani Kelapa di Desa Klabat yang masuk dalam kategori KS III dapat dilihat pada Tabel 11.

Tabel 11. Keluarga Sejahtera Tahap III (KS III) Berdasarkan Indikator yang Tidak Terpenuhi

\begin{tabular}{llrlr}
\hline TINGKAT KS & \multicolumn{2}{c}{ Indikator yang Tidak } & \multicolumn{2}{c}{ Jumlah } \\
& \multicolumn{2}{c}{ Terpenuhi } & $\mathrm{F}$ & $\%$ \\
\hline & 1. & keluarga secara teratur & 1 & 17,5 \\
& dengan suka rela & \\
& memberikan sumbangan & \\
& materil untuk kegiatan & \\
sosial & & &
\end{tabular}

KS III

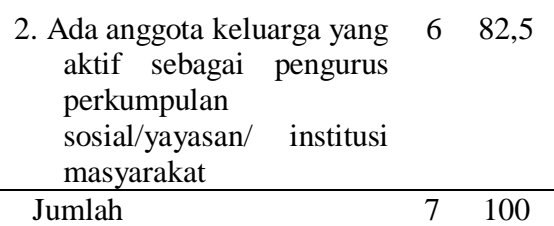

Sumber : Data Primer yang diolah, 2020 
Tabel 12 menunjukkan bahwa sebanyak 7 petani atau $15 \%$ termasuk dalam KS III dengan indikator yang tidak dapat dipenuhi paling banyak adalah peran dalam masyarakat yaitu ada anggota keluarga yang aktif sebagai pengurus perkumpulan sosial sebanyak $82,5 \%$ dan indikator interaksi sosial dengan dengan lingkungan yaitu keluarga secara teratur dan suka rela memberikan sumbangan materil untuk kegiatan sosial sebanyak $17,5 \%$.

Sedangkan sebanyak 7 petani atau $15 \%$ termasuk dalam KS III Plus. Keluarga petani kelapa di Desa Klabat yang berhasil mencapai tahap kesejahteraan paling puncak ini dikarenakan bisa memenuhi dari 21 indikator tahapan keluarga sejahtera dari BKKBN, yaitu tingkat kesejahteraan yang sesungguhnya (kesejahteraan keluarga secara ekonomi dan sosial).

\section{KESIMPULAN DAN SARAN}

\section{Kesimpulan}

Tingkat Kesejahteraan keluarga petani kelapa di Desa Klabat, rata-rata masuk ke dalam kategori KS II. Hasil penelitian ini menunjukkan, masih ada keluarga KS I belum bisa mencapai tingkat kesejahteraan KS II, sebagian besar karena indikator keluarga pasangan usia subur dengan dua anak atau lebih yang menggunakan alat/obat kontrasepsi, belum bisa terpenuhi. Keluarga KS II belum bisa menjadi keluarga KS III, sebagian besar karena indikator penghasilan keluarga yang ditabung dalam bentuk uang atau barang, belum bisa terpenuhi. Keluarga KS III belum bisa menjadi keluarga KS III plus, sebagian besar karena indikator peran dalam masyarakat, belum bisa terpenuhi.

\section{Saran}

1. Peningkatan kesejahteraan keluarga petani di Desa Klabat harus lebih diarahkan pada pengembangan usaha ekonomi keluarga dan memberikan motivasi tentang pentingnya pendidikan dalam keluraga.

2. Untuk meningkatkan tahapan kesejahteraan keluarga petani kelapa, perlu memperhatikan hal-hal yang tidak dapat dipenuh indikator KS I agar dipenuhi untuk bisa masuk ke tahapan selanjutnya.
3. Perlu penelitian lanjutan untuk membandingkan apakah pengukuran yang dilakukan peneliti sama atau berbeda dengan data di desa. Karena dampaknya akan membuat banyak bantuan dari pemerintah akan salah sasaran.

\section{DAFTAR PUSTAKA}

Anonim, 2015. Badan Kependudukan Dan Keluarga Berencana Nasional. Pengertian Keluarga Sejahtera menurut BKKBN Banjarmasin. BKKBN Pusat Provinsi Kalimantan Selatan.

Anonim, 2019. Gambaran Umum Desa Klabat, Diakses pada http://Idesa klabat.blogspot.com/2014/12/gambaranumum-desa.htm. 25 febuari 2020.

Bertham, Y. H. 2011. Peranan Perempuan Dalam Perekonomian Keluarga Dengan Memanfaatkan Sumberdaya Pertanian. Jurnal AGRISEP. Jurusan Sosial Ekonomi Pertanian Fakultas Pertanian Univeristas Bengkulu. Bengkulu.

BPS. 2009. Statistik Indonesia 2009. Jakarta: BPS Ikbal, B, M. 2014. Kontribusi Pendapatan Agribisnis Kelapa Pada Pendapatan Kelurga Petani di Kabupaten Gorontalo. Program Studi Agroteknologi Fakultas Ilmu-Ilmu Pertanian. Universitas Negeri Gorontalo.

Liby, R, L. 2017. Perbandingan Tingkat Kesejahteraan Keluarga Petani Padi Sawah dan Petani Jagung di Desa Matani Kecamatan Tumpaan Kabupaten Minahasa Utara. Jurusan Sosial Ekonomi Universutas Sam Ratulangi. Skripsi. Manado.

Pratiwi, A. P \& Rondhi, M. 2018. Distribusi Kepemilikan Lahan Pertanian dan Pendapatan Usahatani di Wilayah Perkotaan Kabupaten Jember. Programm Studi Agribisnis, Fakultas Pertanian, Universitas Jember.

Sunarti, Euis. 2011. kependudukan dan kesejahteraan keluarga; isu strategis dalam analisis dampak kependudukan terhadap aspek sosial ekonomi. Bogor : Fakultas Ekologi Manusia IPB.

Suratiyah. 2008. Ilmu Usahatani. Penebar Swadaya. Jakarta. 25

Undang-Undang Republik Indonesia Nomor 52 Tahun 2009. Perkembangan Kependudukan dan Pembangunan Keluarga. 